\title{
Structural Development of HDPE in Injection Molding
}

\author{
R. A. Sousa, ${ }^{1,2}$ R. L. Reis, ${ }^{1}$ A. M. Cunha, ${ }^{1}$ M. J. Bevis ${ }^{2}$ \\ ${ }^{1}$ Department of Polymer Engineering, University of Minho, 4800-058 Guimarães, Portugal \\ ${ }^{2}$ Wolfson Centre for Materials Processing, Brunel University, Uxbridge, Middlesex, UB8 3PH, United Kingdom
}

Received 17 August 2002; accepted 18 September 2002

\begin{abstract}
This study investigated some relevant structure/properties relationships in shear-controlled orientation in injection molding (SCORIM) of high-density polyethylene (HDPE). SCORIM was used to deliberately induce a strong anisotropic character in the HDPE microstructure. Three grades with different molecular weight characteristics were molded into tensile test bars, which were subsequently characterized in terms of the mechanical behavior by tensile tests and microhardness measurements. The structure developed upon processing was also characterized by polarized light microscopy (PLM), scanning electron microscopy (SEM), differential scanning calorimetry (DSC), and wide-angle X-
\end{abstract}

ray diffraction (WAXD). SCORIM allows the production of very stiff molded parts, exhibiting a very well-defined laminated morphology. This morphology is associated with both an M-shaped microhardness profile and a pronounced mechanical anisotropy. These characteristics are supported by an analogous variation in the crystallinity and a high level of molecular orientation, as indicated, respectively, by calorimetric measurements and X-ray diffraction results. (C) 2003 Wiley Periodicals, Inc. J Appl Polym Sci 89: 2079-2087, 2003

Key words: polyethylene (PE); crystallization; injection molding; structure-property relationships

\section{INTRODUCTION}

The simple molecular configuration of polyethylene (PE) makes it prone to the development of strong molecular orientation when adequately processed. ${ }^{1-12}$ Some examples of processing techniques that can induce strong levels of anisotropy in PE include hydrostatic extru$\operatorname{sion}^{1-3}$ and processes based on injection molding such as high-pressure injection molding, ${ }^{4-6}$ elongational flow injection molding, ${ }^{7-9}$ and shear-controlled orientation in injection molding (SCORIM). ${ }^{10-12}$

In hydrostatic extrusion, a billet of material at a temperature below its melting point is forced against a die, using a hydrostatic fluid at very high levels of pressure. ${ }^{1-3}$ Under these conditions, the molecular rearrangement introduced in PE as a result of the crosssectional reduction originates in a highly orientated structure and substantial mechanical performance enhancement, ${ }^{1-3}$ with values of the modulus and strength up to $50 \mathrm{GPa}$ and $500 \mathrm{MPa}$, respectively. Conversely to solid-state processing methods like hydrostatic extrusion, in high-pressure injection molding, the polymer above its melting temperature is injected into a mold cavity at very high levels of pressure (to $500 \mathrm{MPa}$ ). Using proper filling rates and

Correspondence to: R. A. de Sousa (rasousa@dep. uminho.pt).

Contract grant sponsor: Subprograma Ciência e Tecnologia do $2^{\circ}$ Quadro Comunitário de Apoio, Ministério da Ciência e Tecnologia (Portugal).

Journal of Applied Polymer Science, Vol. 89, 2079-2087 (2003) (C) 2003 Wiley Periodicals, Inc. adequate gate geometries, it is possible to induce high orientation levels in molded PE using this technique. Typical values of the modulus and strength reported for PE molded by this method are, respectively, 12 $\mathrm{GPa}$ and $260 \mathrm{MPa}$.

Earlier work by Keller and Odell ${ }^{13}$ used the chainstretching effect of elongational flow within a capillary for achieving high-modulus PE fibers. This approach was used as a technological template for the development of elongational flow injection molding. ${ }^{7-9}$ This latter technique differentiates from high-pressure injection molding by the lower processing pressures and by the specific mold geometry intended to purposely induce an axial elongational flow. Values of the strength to up $160 \mathrm{MPa}$ have been reported for PE processed by this route. ${ }^{7}$

Conversely to the previously referred techniques, shear-controlled orientation in SCORIM is based on the application of a macroscopic shear stress field to the melt-solid interface using two hydraulic-actuated pistons. ${ }^{10-12,14}$ This process, originally designated as multiple live-feed molding, was developed by Allan and Bevis ${ }^{14}$ in 1986. SCORIM processing of PE results in a strong mechanical performance enhancement when compared to conventional injection molding, ${ }^{10-12}$ with values of the tensile modulus and tensile strength above 7.0 and $150 \mathrm{MPa}{ }^{11}$ The high mechanical performance of SCORIM-processed PE was shown to be related to the existence of a shish-kebabrow nucleated structure as proved by calorimetric and X-ray diffraction (XRD) studies. ${ }^{11}$ The high anisotropy of SCORIM-molded PE is explained by the highly 
anisotropic character of the chain-extended crystallized fiber (shish) and the interlocking effect between adjacent epitaxially grown platelets (kebab). ${ }^{15-17}$ The development of these anisotropic entities is itself strongly dependent on the molecular weight and molecular weight distribution of the molten polymer, ${ }^{16,17}$ which may be of crucial importance when optimizing the injection molding of PE. Within this perspective, the aim of the present study was twofold: (i) the investigation of the mechanical performance of three different SCORIM-processed high-density polyethylene (HDPE) grades and (ii) the establishment of the respective structure/property relationships in the light of the molecular weight. To accomplish such objectives, SCORIM was used to mold several HDPE grades into test bars, which were subsequently characterized in terms of the mechanical behavior by tensile tests and microhardness measurements. The structure developed upon processing was characterized by polarized light microscopy (PLM) and scanning electron microscopy (SEM) together with differential scanning calorimetry (DSC) and XRD.

\section{EXPERIMENTAL}

\section{Materials}

Three HDPE grades were studied, namely: (i) Vestolen A 6016, supplied by Vestolen GmbH (Gelsenkirchen, Germany) with a melt-flow rate (MFR) of $26 \mathrm{~mL} / 10$ min $\left(190^{\circ} \mathrm{C}, 49 \mathrm{~N}\right)$, a number-average molecular weight $\left(M_{n}\right)$ of 56,212 , a weight-average molecular weight $\left(M_{w}\right)$ of 58,000 , and a polydispersity $\left(M_{w} / M_{n}\right)$ of 1.0; (ii) Hostalen GM 9255 F, supplied by Elenac $\mathrm{GmbH}$ (Wesseling, Germany) with an MFR of 0.37 $\mathrm{mL} / 10 \mathrm{~min}\left(190^{\circ} \mathrm{C}, 49 \mathrm{~N}\right)$, an $M_{n}$ of 18,000 , an $M_{w}$ of 282,000, and an $M_{w} / M_{n}$ of 15.7; and (iii) Stamylan HD8621, supplied by DSM Research BV (Geleen, The Netherlands) with an MFR of $0.15 \mathrm{~mL} / 10 \mathrm{~min}\left(190^{\circ} \mathrm{C}\right.$, $49 \mathrm{~N})$, an $M_{n}$ of 7000 , an $M_{\mathrm{w}}$ of 210,000 , and an $M_{w} / M_{n}$ of 29 .

\section{SCORIM}

All the studied materials were molded in a Demag D-150 NCIII-K injection-molding machine equipped with a SCORIM device into axisymmetric tensile test bars with a circular cross section of $5 \mathrm{~mm}$ of diameter and $25 \mathrm{~mm}$ of gauge length. The SCORIM equipment employed consists of a device that is attached to the injection nozzle and is composed of a runner circuit that divides the melt stream into two channels where two hydraulically actuated pistons are operated during the holding pressure stage.

Conversely to conventional injection molding, where the molten material solidifies under the influence of an almost static pressure, in SCORIM, the molten polymer is continuously displaced inside the mold by the action of the hydraulic pistons, which causes, as the solidification takes place progressively from the mold wall to the core, the application of a macroscopic shear field at the melt/solid interface. This effect is accomplished using the SCORIM mode A of operation that corresponds to the out-of- phase oscillation of the pistons. Other possible modes include mode B (in phase oscillation of the pistons) and mode $C$ (compression of the pistons at a constant pressure). These operation modes can be combined sequentially in several stages during the injectionmolding cycle. In this specific study, all the studied materials were molded using a similar molding program based on two stages: the first based on mode A and the second based on mode $\mathrm{C}$.

\section{Mechanical characterization}

The samples produced were tensile tested under a controlled environment $\left(23^{\circ} \mathrm{C}\right.$ and $\left.55 \% \mathrm{RH}\right)$ on an Instron 4505 universal mechanical testing machine. An Instron 2630 resistive extensometer with $10 \mathrm{~mm}$ of gauge length was used. The crosshead speed was 5 $\mathrm{mm} / \mathrm{min}\left(8.3 \times 10^{-5} \mathrm{~m} / \mathrm{s}\right)$ until $1.5 \%$ strain, to determine more accurately the modulus, and then increased to $50 \mathrm{~mm} / \mathrm{min}$ until fracture $\left(8.3 \times 10^{-4} \mathrm{~m} / \mathrm{s}\right)$. For each tensile test, the tangent modulus $\left(E_{t}\right)$, the ultimate tensile strength (UTS), and the strain-at-break point $\left(\varepsilon_{b}\right)$ were determined.

The variation in the mechanical performance and anisotropy along the thickness of the injection-molded parts was also investigated by microindentation hardness (further abbreviated as microhardness). The experiments were carried out at room temperature in selected specimens, along the cross-section thickness, in a Leica VMHT30A equipped with a Vickers diamond indenter, using a load of $2.94 \mathrm{~N}$ and a dwell time of $5 \mathrm{~s}$.

\section{Structural characterization}

SEM was performed for fractographic analysis on selected sets on a Leica Cambridge Stereoscan LS360 scanning electron microscope. All the surfaces were mounted onto a copper stub and coated by ion sputtering with a $\mathrm{Au} / \mathrm{Pd}$ alloy prior to examination.

Samples to be used for optical microscopy were prepared by cutting the tensile test bars at the gaugelength region and mounting the obtained sections in an epoxy resin. After curing, a microtome was used to cut slices in the longitudinal direction from the obtained specimen with an average thickness of $15 \mu \mathrm{m}$. These slices were observed by optical PLM in an Olympus BH-A microscope.

Calorimetric studies were performed on a differential scanning calorimeter Perkin-Elmer DSC 7 to as- 
TABLE I

Tensile Properties Range of SCORIM-processed HDPE Grades

\begin{tabular}{lccc}
\hline \multicolumn{1}{c}{ Grade } & Et (GPa) & UTS (MPa) & $\varepsilon_{b}(\%)$ \\
\hline Vestolen A6016 & $2.03-3.63$ & $45.9-66.2$ & $17.1-65.6$ \\
Hostalen GM 9255F & $2.79-5.74$ & $69.9-91.9$ & $12.0-46.4$ \\
Stamylan HD8621 & $4.87-7.36$ & $102.8-161.3$ & $13.8-45.4$
\end{tabular}

sess the variation in the microstructure induced by the processing route along the part diameter. This variation was investigated by calorimetric analysis of longitudinal samples obtained from the gauge-length region at different distances from the mold wall. Each sample was placed in an aluminum pan and heated at a rate of $10.0^{\circ} \mathrm{C}$ per minute from 40 to $200^{\circ} \mathrm{C}$. The mass crystallinity was calculated using an enthalpy of fusion for a $100 \%$ crystalline PE of $296 \mathrm{~J} / \mathrm{g} .{ }^{18}$

$\mathrm{Ni}$-filtered $\mathrm{CuK} \alpha$ radiation was used to obtain XRD patterns in a Philips microcamera. These patterns were used to assess the preferred orientation of the tensile test bar specimens at the gauge-length region. The X-ray beam was oriented parallel to the thickness of the sample and perpendicular to the main direction of flow (MDF). An aperture of $100 \mu \mathrm{m}$ of diameter was used to define the position and cross section of the incident X-ray beam. The XRD patterns were obtained for the moldings at $1.0 \mathrm{~mm}$ from the edge of the moldings.

\section{RESULTS AND DISCUSSION}

\section{Mechanical behavior}

Table I presents the range of mechanical property variation of SCORIM-processed HDPE, in terms of the tangent modulus $(E t)$, the ultimate tensile strength (UTS), and the strain at break ( $\varepsilon b)$. Vestolen A6016 moldings presented the lowest stiffness and strength values, being followed in order of magnitude by Hos-

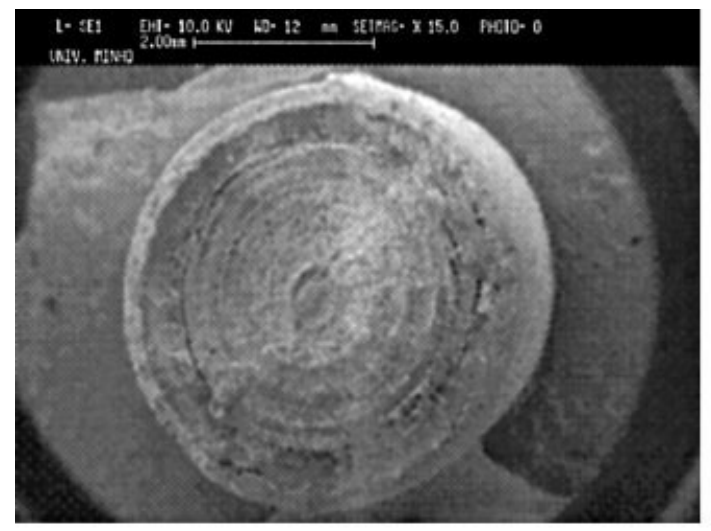

(a) talen GM 9255F and Stamylan HD8621 moldings. The large range of mechanical performance variation observed for HD8621 demonstrates the SCORIM ability in controlling the microstructural development of PE and thus the respective mechanical behavior. Furthermore, this grade has been a matter of an intensive processing optimization study, which enabled the identification of the most relevant processing parameters concerning the control of mechanical performance. ${ }^{11}$ In spite of this, it is clear that the SCORIM application enhances both the stiffness and the strength for all these materials as compared to conventional injection molding for which typical values of Et and UTS are in the ranges of 1.2-1.5 GPa and 35-45 $\mathrm{MPa}$, respectively. Although this positive trend is common to the three polymers investigated, the magnitude of the improvements achieved for each case is different, being smaller for the lower molecular weight polymer. As previously mentioned, molecular weight is a determining factor in the development of the shish-kebab structure of PE. ${ }^{16,17}$ This fact is the outcome of the competing process between chain extension and chain relaxation as determined by the strain rate and the relaxation time. ${ }^{16,19}$ Longer molecules, that is, higher molecular weight materials, exhibit longer relaxation times, which makes them more prone to chain extension during processing.

\section{Morphology developed upon SCORIM application}

Figure 1 presents the typical tensile fracture surface of SCORIM-processed Vestolen A 6016 moldings as observed by SEM. SCORIM induces the formation of a clear-layered morphology. Figure 1(b) suggests the existence of alternate layers with dissimilar mechanical behavior. A previous study ${ }^{12}$ showed that the interruption of shear between piston strokes results in a sandwichlike microstructure featuring alternating spherulitic and shish-kebab zones corresponding, re-

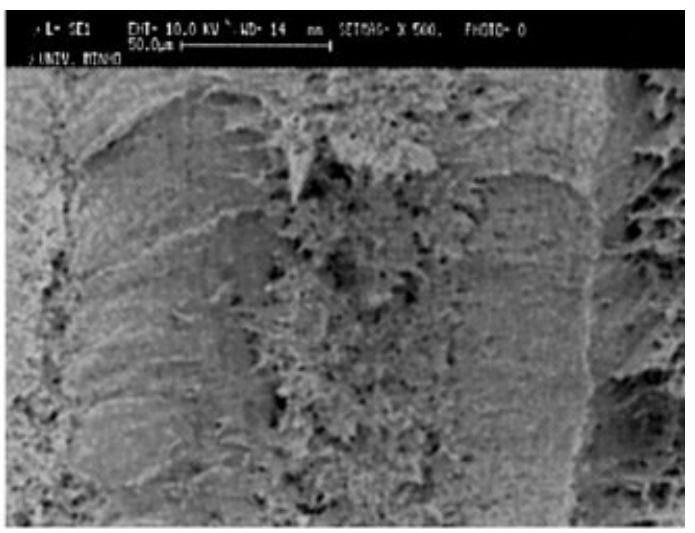

(b)

Figure 1 (a) Typical tensile fracture surface of SCORIM-processed Vestolen A 6016 and (b) respective detail. 


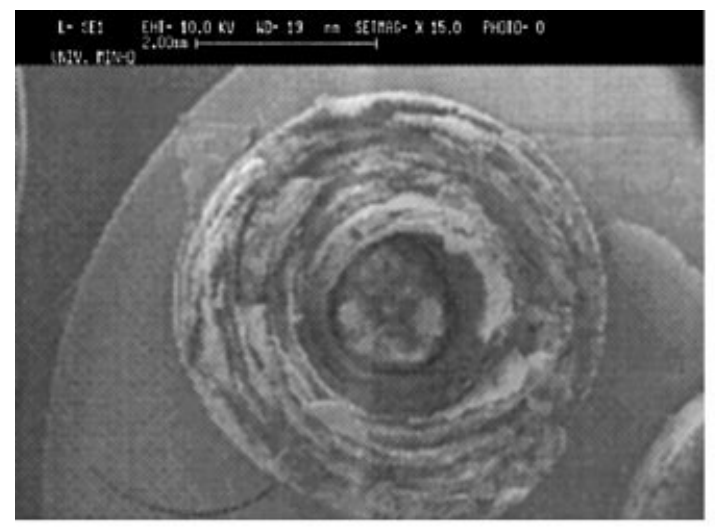

(a)

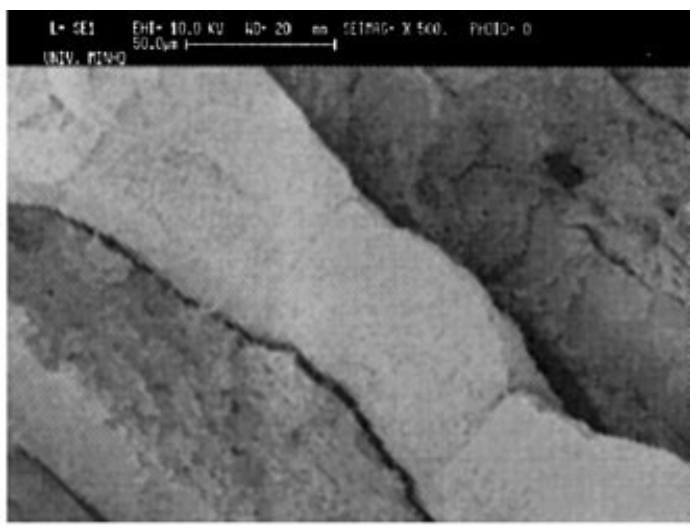

(b)

Figure 2 (a) Typical tensile fracture surface of SCORIM-processed Hostalen GM $9255 \mathrm{~F}$ and (b) respective detail.

spectively, to almost isotropic and anisotropic regions. This layered morphology is again observed in Figure 2 for the tensile fracture surface of GM $9255 \mathrm{~F}$ moldings. The discontinuous morphology results from the melt flow in consecutive alternating directions that is imposed by the SCORIM mode A of operation. In spite of the morphological similarity between the two materials, the GM $9255 \mathrm{~F}$ grade appears to exhibit very strong induced orientation in the MDF as suggested by the lack of adhesion between consecutive layers [see Fig. 2(b)].

Figure 3 presents PLM photographs of the longitudinal cross section of SCORIM-processed Vestolen A 6016. The laminated morphology developed is also evident in Figure 3(a). This morphology comprises three different zones: a main spherulitic core [Fig. 3(b)], a highly birefringent layered region [observable in both Fig. 3(b) and (c)], and a skin zone close to the mold wall [observable at bottom right of Fig. 3(d)]. Earlier works ${ }^{13,20}$ evidenced the high birefringence of PE crystallized from an orientated melt. This birefringence disappears upon melting of the isotropic matrix but remains at higher temperatures, being associated, at this melting stage, to unmelted orientated fibrils. Measurements in injection-molded bars also indicated high birefringence of $\mathrm{PE}$ as a result of strong molecular orientation, which was observed to be higher at the thin shear zone close to the mold wall. ${ }^{9}$ In SCORIM moldings, the layered region is highly birefringent, which constitutes a manifestation of strong molecular orientation and thus evidence of the SCORIM ability in controlling the bulk structure development of PE.

\section{Microhardness along part thickness}

Microhardness measurements have been recognized as adequate for measuring the anisotropy of orientated PE. ${ }^{21,22}$ In fact, for orientated PE, the Vickers indentations are considerably anisotropic, showing smaller diagonal lengths parallel to the predominant direction of molecular orientation..$^{21,22}$ The indentation anisotropy is explained by the highest stiffness of PE in this direction as a result of the fibril-dominated microstructure, which results in considerable elastic recovery upon load release. This variation in microhardness between orthogonal directions was observed in orientated PE processed by elongational flow injection molding. ${ }^{23}$ In this case, the indentation anisotropy along the part thickness varied consistently with the birefringence, indicating a relationship between mechanical and optical anisotropies.

Figure 4 presents the variation of microhardness along the molding diameter for the three HDPE grades investigated measured in two different directions: parallel and perpendicular to the MDF. Please note that these two directions are defined as the directions of application of load during the microhardness testing and do not correspond to the orientation of the indentation diagonals. So, the microhardness profiles presented here are based on the averaged values of the two indentation diagonals. As a result, each microhardness profile (parallel or perpendicular to MDF) presented in Figure 4 translates, in a different manner, the mechanical behavior of the polymer.

The microhardness profiles along the part diameter, for all the grades and for both directions, exhibit a typical M-pattern, with maximum values at intermediate distances from the mold wall and lowest microhardness values at both the core and the skin regions. The lower hardness at the skin is the result of the very rapid cooling of the polymer adjacent to the mold wall, which causes freezing of the melt orientation but hinders crystallization. Below the skin zone, in the so-called layered region, which makes the transition to the molding core, the higher hardness is associated with a highly anisotropic crystalline structure arising as a consequence of the shear field applied. From the three grades investigated, Vestolen A 6016 presents 
(a)

(b)
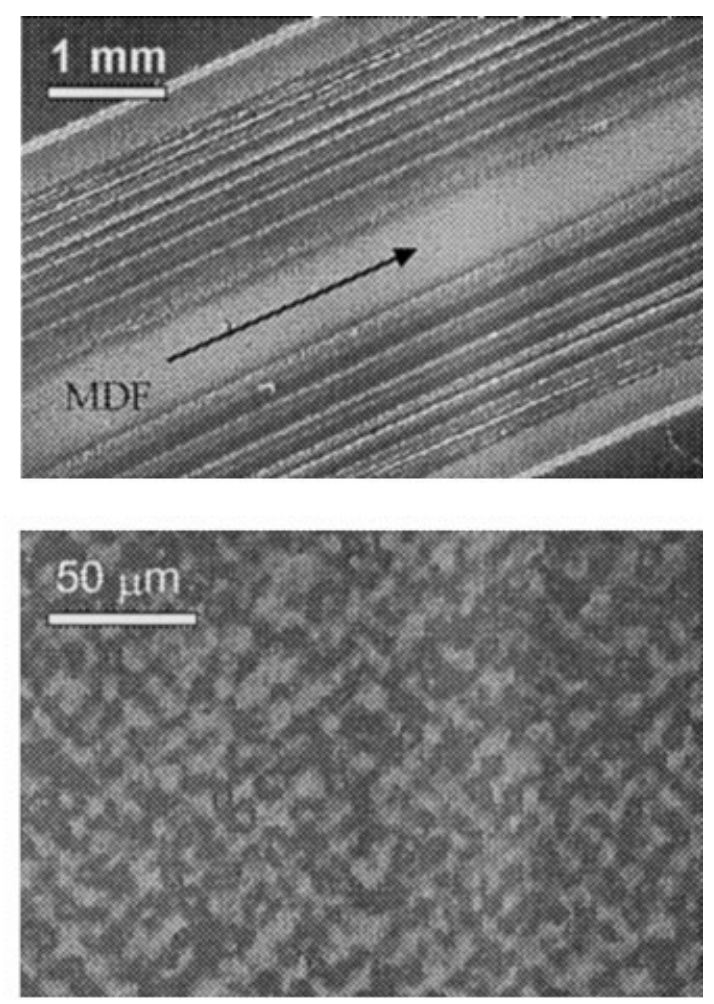

(c)
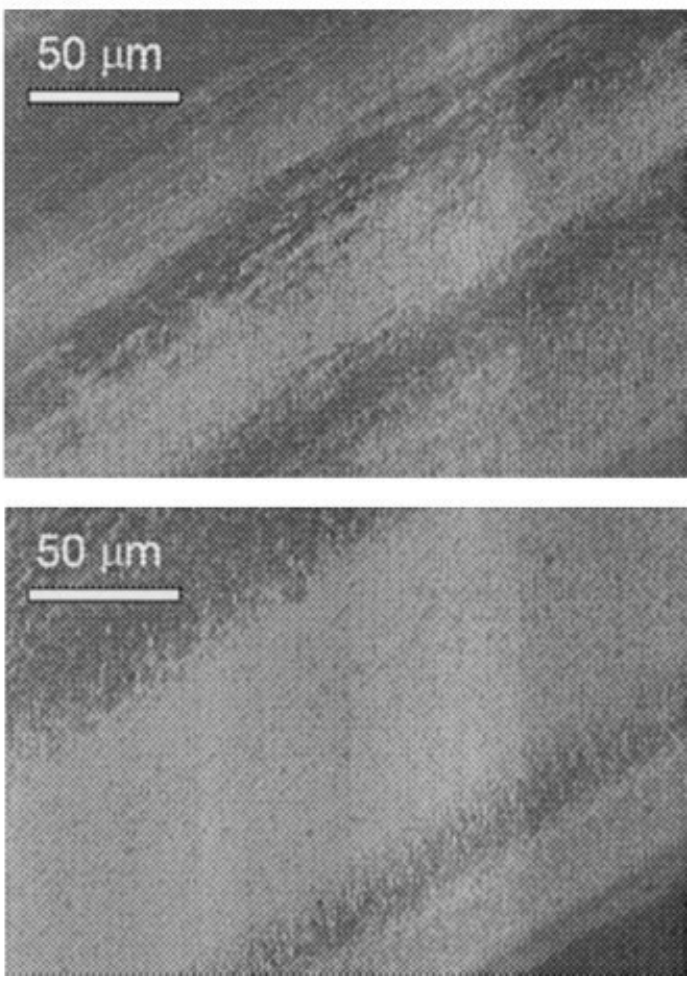

(d)

Figure 3 PLM photographs of the longitudinal cross section of SCORIM-processed Vestolen A 6016: (a) overview; (b) central core; (c) transition layer; (d) skin.

the higher average microhardness, which suggests a higher degree of crystallinity for this grade.

The apparent anisotropy of the moldings can be inferred from the difference observed between the microhardness profiles in the parallel and the perpen- dicular directions. In the parallel direction (for which the direction of load application is parallel to the $\mathrm{MDF}$ ), both indentation diagonals are perpendicular to the MDF. Conversely, in the perpendicular direction (for which the direction of load application is 


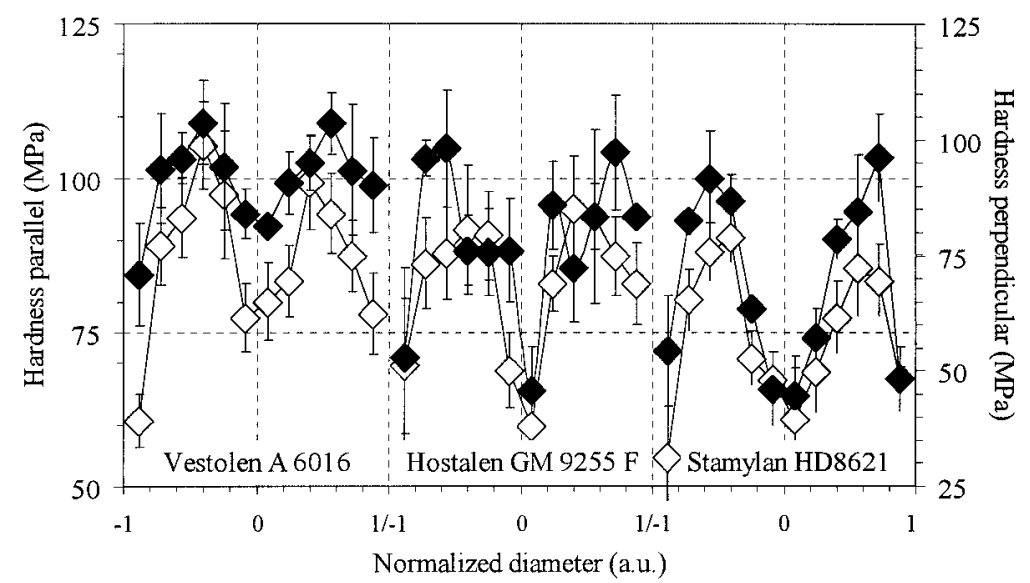

Figure 4 Variation of microhardness along the sample diameter for SCORIM-processed Vestolen A 6016, Hostalen GM 9255 F, and Stamylan HD8621 moldings as calculated from both indentation diagonals after application of load $(\diamond)$ parallel and $(\bullet)$ perpendicular to the MDF.

perpendicular to the MDF), one indentation diagonal is perpendicular to the MDF while the other remains parallel to the MDF. As a consequence, the microhardness in the perpendicular direction tends to be higher due to the larger contribution of the molding anisotropy in this direction. This is particularly evident at the layered region of both high molecular weight PE grades (Hostalen GM 9255 F and Stamylan HD8621), which suggests a higher degree of anisotropy at this region for these grades as compared with Vestolen A 6016. The molding core, especially for Hostalen GM $9255 \mathrm{~F}$ and Stamylan HD8621, are considerably less anisotropic.

\section{Semicrystalline structure}

Figure 5 presents the variation of mass crystallinity along the sample diameter as determined by DSC for SCORIM-processed Vestolen A 6016 [Fig. 5(a)] and Hostalen GM 9255 F [Fig. 5(b)] moldings together with the respective plot of microhardness as a function of mass crystallinity. The crystallinity variation along the part diameter profile exhibits the typical M-shaped curve characteristic of the SCORIM process, which is in agreement with the microhardness profiles previously presented. It is possible to confirm the existence of (i) a low-crystallinity layer corresponding to a rapidly cooled region, (ii) a highly crystalline laminated region developed under shear, and (iii) a highly crystalline core. This morphology differs from the typical one found in conventionally injection-molded parts that feature a thin skin and a large core. ${ }^{24}$ The application of SCORIM induces the formation of an additional intermediate region featuring high crystallinity and high anisotropy. These findings corroborate a previous study involving calorimetric characterization of PE injection-molded under an oscillating stress field, which showed a similar variation in the enthalpy of fusion of PE along the part thickness. ${ }^{25}$

The Vestolen A 6016 moldings are considerably more crystalline than are the Hostalen GM 9255 F moldings, which is interpreted in the light of the respective molecular weight data. Baltá Calleja et al. ${ }^{26}$ reported the inverse dependence of microhardness on the molecular weight for both low-density PE and HDPE as an indirect consequence of the molecular weight parameters on structural factors affecting the microhardness. In the study, the diminution in the microhardness upon the molecular weight increase was attributed to the increase in the thickness of the interlamellar layers. As expected, the variation in mass crystallinity along the part diameter supports the microhardness profiles, making clear the dependence of the microhardness on the microstructure developed and on the molecular parameters.

Vestolen A 6016 moldings exhibit higher mass crystallinity and, consequently, higher average hardness values. Nevertheless, when comparing the dependence of the hardness on the mass crystallinity, Hostalen GM $9255 \mathrm{~F}$ displays a higher dependence of hardness on the mass crystallinity. Between the glass transition and the melting temperature, the hardness of semicrystalline polymers is dependent mostly on the plastic deformation of the crystalline fraction. ${ }^{27}$ However, the molecular weight plays an important role on the development of shish-kebab structures in HDPE. ${ }^{16,28}$ Although Hostalen GM 9255 F is less crystalline, the stepped increase in the hardness with the crystallinity for this case is associated with the higher anisotropy of the crystalline phase-the shish-kebab structure. The great dependence of the mechanical behavior on the molding orientation was shown by the study of Ania et al..$^{29}$ concerning the investigation of the structure formation and respective properties of 
(a)

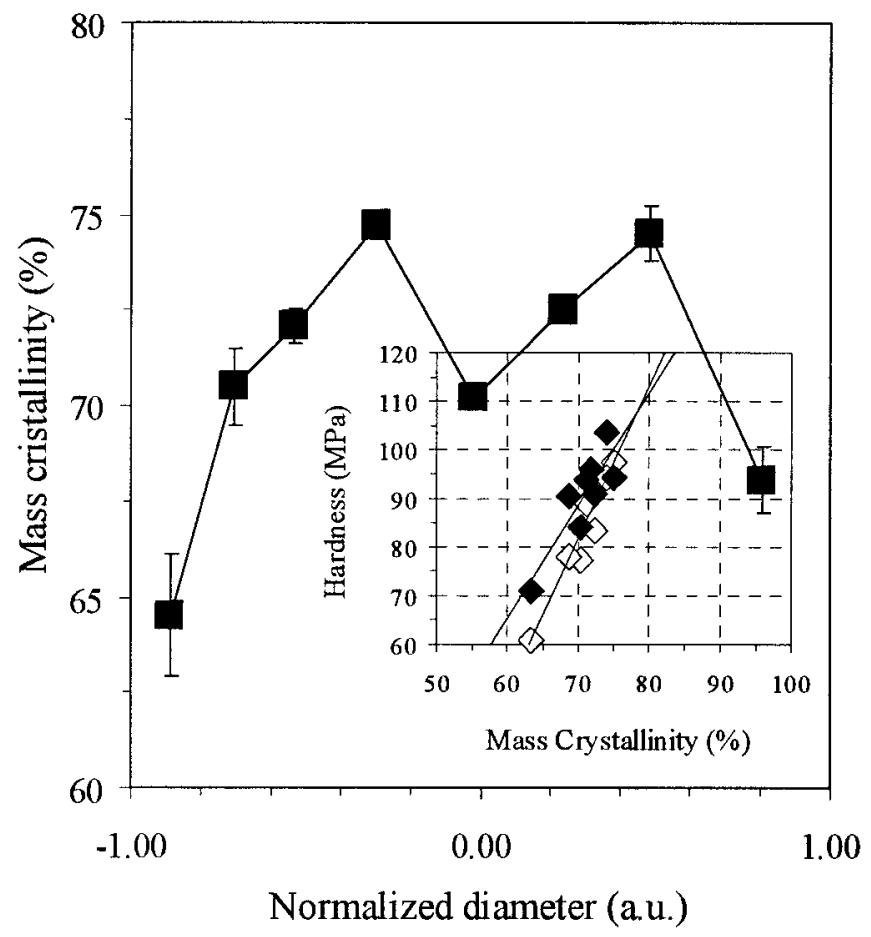

(b)

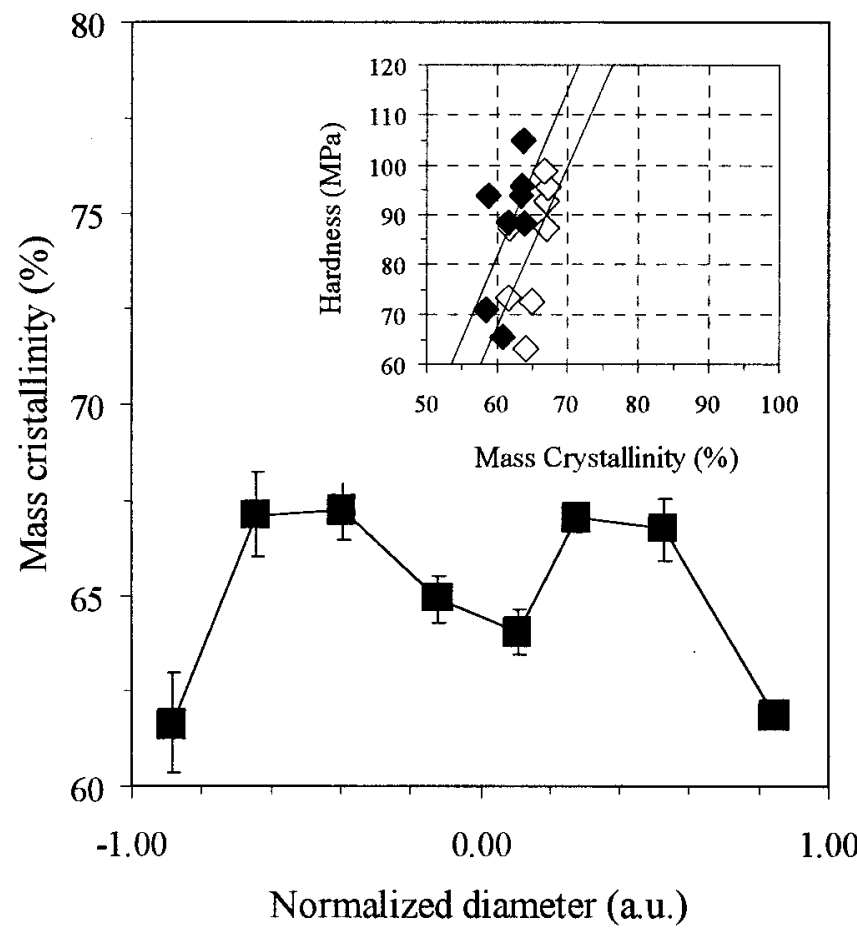

Figure 5 Variation of mass crystallinity along the sample diameter as determined by DSC for SCORIM-processed (a) Vestolen A 6016 and (b) Hostalen GM 9255 F moldings and the respective relationship with the hardness.

orientated HDPE. The increase in orientation of HDPE through the development of the shish-kebab structure contributes to a fivefold increase in tensile strength.

Figure 6 presents WAXD patterns for the three HDPE grades. All the grades exhibit strong (110) and (200) reflections with higher intensities at the equator regions, which indicates pronounced molecular orientation parallel to the MDF. The strong $c$-axis orientation supports the mechanical anisotropy previously observed and is the result of the polymer crystallization under shear. In spite of this pronounced molecular orientation, the Vestolen A 6016 moldings are, for 


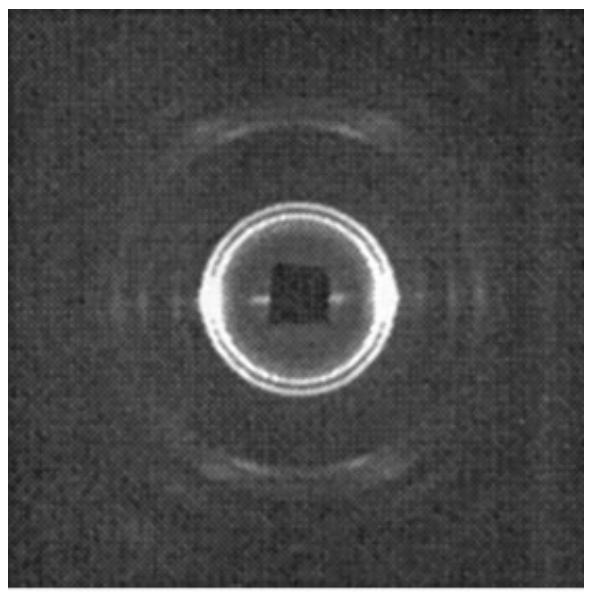

(a)

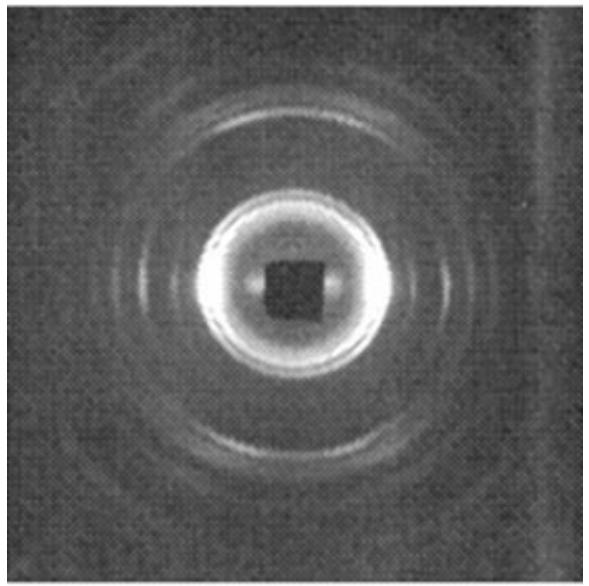

(b)

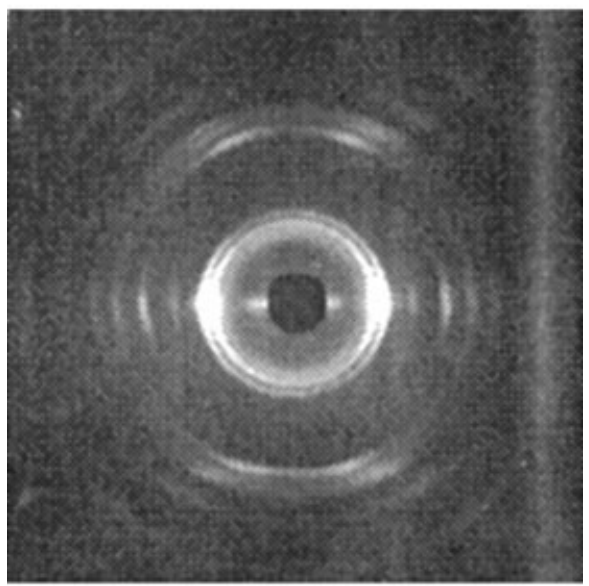

(c)

Figure 6 WAXD patterns for SCORIM-processed (a) Vestolen A 6016, (b) Hostalen GM 9255 F, and (c) Stamylan HD8621 moldings.

the three grades investigated, the more isotropic, as suggested by the minor intensity at the equator. On the contrary, both the Hostalen GM 9255 F and the
Stamylan HD8621 grades exhibit very strong arching of the rings at the (110) and the (200) reflections, which indicates improved orientation as compared to the former case. The higher orientation reported for these two grades (which are simultaneously less crystalline) is a consequence of the extensive shish kebab present in the molded part that sustains the superior mechanical performance and observed mechanical anisotropy.

\section{CONCLUSIONS}

SCORIM is an effective processing tool for the structure development control of semicrystalline polymers such as HDPE. The moldings obtained by this processing route exhibit a typical laminated morphology composed of a main spherulitic core, a skin zone, and a highly birefringent layered region that makes the transition between the two former regions. For all the grades, the microhardness profile along the respective part diameter displays a typical M-pattern, with maximum values at intermediate distances from the mold wall and lowest values at both the core and the skin regions. This variation in microhardness is supported by a similar variation in mass crystallinity as measured by calorimetric studies. Additionally to this variation profile, the difference in microhardness measured between the parallel and the perpendicular directions indicates a high level of anisotropy at the layered region. This molding anisotropy is particularly more evident for the higher molecular weight grades, namely, Hostalen GM 9255 F and Stamylan HD8621. Although microhardness is not directly influenced by the molecular weight, molecular dimensions play a crucial role on the structure development and molding anisotropy and, consequently, on the final mechanical performance. The higher anisotropy of higher molecular weight materials was confirmed by X-ray diffraction and results from the extensive shish-kebab formation during shear application.

One of the authors (R. A. S.) acknowledges the financial support by the Subprograma Ciência e Tecnologia do $2^{\circ}$ Quadro Comunitário de Apoio, Ministério da Ciência e Tecnologia (Portugal).

\section{References}

1. Parsons, B.; Ward, I. M. Plast Rubb Process Appl 1982, 2, 215224.

2. Ward, I. M. Plast Rubb Process Appl 1993, 19, 7-13.

3. Biggs, D. M Polym Eng Sci 1988, 28, 830-841.

4. Kubát, J.; Månson, J. A. Polym Eng Sci 1983, 23, 869-876.

5. Kubát, J.; Månson, J. A.; Rigdahl, M. Polym Eng Sci 1983, 23, 877-882.

6. Boldizar, A.; Månson, J. A.; Rigdahl, M. J Appl Polym Sci 1990, $39,63-71$ 
7. Bayer, R. K.; Zachmann, H. G.; Baltá Calleja, F. J.; Umbach, H. Polym Eng Sci 1989, 29, 187-192.

8. Lopez Cabarcos, E.; Bayer, R. K.; Zachmann, H. G.; Baltá Calleja, F. J.; Meins, W. Polym Eng Sci 1989, 29, 193.

9. Bayer, R. K.; Baltá Calleja, F. J.; Lopez Cabarcos, E.; Zachmann, H. G.; Paulsen, A; Brüning, F.; Meins, W. J Mater Sci 1989, 24, 2643-2652.

10. Mano, J. F.; Sousa, R. A.; Reis, R. L.; Cunha, A. M.; Bevis, M. J. Polymer 2001, 42, 6187-6198.

11. Kalay, G.; Sousa, R. A.; Reis, R. L.; Cunha, A. M.; Bevis, M. J. J Appl Polym Sci 1999, 73, 2473-2483.

12. Ogbonna, C I.; Kakay, G.; Allan, P. S.; Bevis, M. J. J Appl Polym Sci 1995, 58, 2131.

13. Keller, A.; Odell, J. A. J Polym Sci Polym Symp 1978, 63, 155164.

14. Allan, P. S.; Bevis M. J. Plast Rubb Process Appl 1987, 7, 3-10.

15. Odell, J. A.; Grubb, D. T.; Keller, A. Polymer 1978, 19, 617-626.

16. Bashir, Z.; Odell, J. A.; Keller, A. J Mater Sci 1984, 19, 3713-3725.

17. Bashir, Z.; Odell, J. A.; Keller A. J Mater Sci 1986, 21, 3993-4002.

18. Melkern, L.; Alamo, R. G. In Physical Properties of Polymers Handbook; Mark, J. E., Ed.; American Institute of Physics: New York, 1996.
19. Mackley, M. R.; Keller, F. R. S. Philos Trans R Soc Lond A 1975, 278, 29-66.

20. Grubb, D. T.; Odell, J. A.; Keller, A. J Mater Sci 1975, 10, $1510-1518$

21. Baltá Calleja, F. J.; Basset, D. C. J Polym Sci Polym Symp 1977, 58, 157-167.

22. Baltá Calleja, F. J.; Rueda, D. R.; Porter, R. S.; Mead, W. T. J Mater Sci 1980, 15, 765-772.

23. Rueda, D. R.; Bayer, R. K.; Baltá Calleja, F. J.; Zachmann, H. G. J Macromol Sci Part B Phys 1989, 28, 267-284.

24. Godinho, J. S.; Cunha, A.; Crawford, R. J. Plast Rubb Compos 2000, 29, 316-328.

25. Guan, Q.; Xaizhi, K.; Ji, J.; Zhu, J. J Appl Polym Sci 1995, 55,1797-1804.

26. Baltá Calleja, F. J.; Giri, L.; Michler, G. H.; Naumann, I. Polymer 1997, 38, 5769.

27. Baltá Calleja, F. J.; Fakirov, S. Microhardness of Polymers; Cambridge University: Cambridge, 2000.

28. Ania, F.; Baltá Calleja, F. J.; Bayer, R. K.; Tshmel, A.; Naumann, I.; Michler, G. H. J Mater Sci 1996, 31, 4199-4206.

29. Ania, F.; Baltá Calleja, F. J.; Bayer, R. K. Polymer 1992, 33, 233-238. 